\title{
Definition of Fuel and Lubricant Consumption Rates and Production of Tractor Units As Part of John Deere Tractors Andrey Ivanov
}

Northern Trans Ural State Agricultural University, Tyumen, Russia

\section{Abstract}

Tractors are mainly applied in agriculture. The share of import in the structure of tractor machinery market is constantly growing. One of the information sources for the optimization of the machine and tractor fleet and the development of standards to satisfy the needs of typical farms in tractors and agricultural machines for crop production are the performance standards of machinery and fuel consumption. The recommended norms of fuel production and consumption imply the rational use of shift time, optimal composition of machine-tractor units and effective operation modes of tractors and self-travelling agricultural machines. In recent years, many tractors and

Corresponding Author:

Andrey Ivanov

Received: 25 October 2019

Accepted: 15 November 2019

Published: 25 November 2019

Publishing services provided by Knowledge E

(c) Andrey Ivanov. This article is distributed under the terms of the Creative Commons

Attribution License, which permits unrestricted use and redistribution provided that the original author and source are credited.

Selection and Peer-review under the responsibility of the AgroSMART 2019 Conference Committee. agricultural machines of foreign companies, including John Deere, are working in the fields of Trans-Urals, Siberia and Russia as a whole. The standards of production and consumption of fuels and lubricants for these agro-climatic conditions are not available for all machine-tractor units. Therefore, it is becoming ever more relevant for agricultural producers to develop such. The studies to establish fuel consumption standards and performance rates of machine-tractor units as part of John Deere tractors were carried out in the fields of agricultural enterprises of the Tyumen Region. The paper presents the results of the study. For example, the productivity of a tractor for a field located at a distance of $5--6 \mathrm{~km}$ and an average length of furrow of $1300 \mathrm{~m}$ can be in the range of 5.8--6.0 ha/h. Taking into account natural and climatic conditions and different physical and mechanical composition of soil, as well as configuration of fields and length of furrows during processing, the data on the consumption of basic lubricants were obtained. Recommendations on the use of consumption rates for fuels and lubricants of modern tractors in various technological operations in agriculture will greatly facilitate planning and calculation of operating costs of machine-tractor units. The paper considers recommendations on the use of correction factors to the nominal range of fuel consumption depending on soil type for John Deere tractors of the $9^{\text {th }}$ series on the example of disk tillage. Software for economic evaluation of agricultural machinery as part of agricultural technology was developed.

Keywords: fuel consumption, lubricants, machine-tractor unit performance, John Deere, Tyumen Region. 


\section{Introduction}

The use of imported equipment in agricultural enterprises of the Russian Federation in order to improve the technological infrastructure sets the task of accurate and effective calculation of a machine-tractor fleet (MTF) for specific farms operating in the regions of Russia. The present and the future of agricultural production are inextricably linked to its equipment with high-performance, energy-saturated modern equipment, including tractor machinery [1].

Foreign agricultural tractors at their higher cost differ significantly from Russian and Belarusian of the same traction class and capacity not only by lower operating weight, attractive appearance, quality of assembly and painting, but also by a number of other advantages, in particular higher technical level of assemblies, units and systems, high comfort and low labor intensity of maintenance. Due to these advantages, the volume of imported equipment to the Russian Federation reached about $42 \%$ of the total volume of tractors.

Currently the share of import (Case IH, New Holland, John Deere, etc.) in the structure of the tractor machinery market is constantly growing. The efficient use of agricultural machinery is only possible if each enterprise has a regulatory framework at all levels of planning forming the basis for reasonable economy regime. The costs of various types of resources, including operational materials, are regulated through planning on the basis of consumption rates.

The information sources to define the consumption of fuels and lubricants and the performance of tractors and agricultural machines for crop production are the following: technical characteristics of tractors and agricultural machines; book value of machines, standard charges for renovation, repair and maintenance; sowing areas and peculiarities of natural and industrial conditions; machinery performance rates and fuel consumption; duration of works; flow process charts for crop cultivation [2].

Performance rates, consumption of fuels and lubricants are developed taking into account the main standard-setting factors (length of furrow, slope ratio, field configuration, rockiness, field relief and height above sea level), which significantly affect the productivity of machine-tractor units and are determined during certification of fields, meadows, cultural pastures and perennial plantations. These norms take into account agricultural and other factors affecting the value of norms [3].

Regulation of fuel consumption is the establishment of its permissible value under certain operating conditions for a specific model (modification) of a motor vehicle. Regulation of fuel consumption is performed via a base norm (base flow rate) and 
the corresponding set values of increases (decreases), as well as values of additional fuel consumption.

The standard for tractor operation is the basic fuel consumption when performing a certain type of work in specific conditions per a machine-hour or per a performed operation. The recommended norms of fuel production and consumption imply the rational use of shift time, optimal composition of machine-tractor units and effective operation modes of tractors and self-travelling agricultural machines.

Based on the developed standards along with the definition of a shift task and a salary amount (remuneration of labor) the production departments and farms in general can determine the amount of works for each operation according to flow charts on cultivation, wages fund, quantity and structure of mechanical means by the variety of cars necessary for timely performance of agricultural works, fuel quantity, number of machine operators, etc.

The definition of labor standards for mechanized field works and their clarification happens in cases when the working conditions for which the standards were calculated have changed, as well as in cases when new equipment arrives. The farm can clarify the rules in the compendium or develop new rules that will be in force before the introduction of temporary or standard guidelines developed by the regulatory network.

In order to develop or refine the standards, it is necessary to measure the operation of a corresponding tractor unit (not less than three times), develop a design structure of a working shift, set the production time per hour of a normal time and determine the production rate for specific production conditions.

The standards of production and consumption of fuels and lubricants for agro-climatic conditions are not available for all machine-tractor units. Therefore, it is becoming ever more relevant for agricultural producers to develop such.

\section{Methods and Equipment}

The purpose of the study is to establish the consumption of fuels and lubricants and the performance rate of John Deere tractors in real conditions.

The study of machine-tractor units was carried out in the fields of The Tyumen Region in agricultural enterprises of LLC SP Malyshenskoe of Golyshmanovsky district, LLC SP Sitnikovskoe of Omutinsky district, ZAO Uspenskoe of Tyumen district, LLC Agrofirma $\mathrm{KR}$ and MM of Uporovsky district. Enterprises of various districts of Tyumen Region are selected taking into account natural and climatic conditions, as well as physical and mechanical composition of soil. 
According to the research technique, a flow meter of diesel fuel IP 263 RE was installed additionally in the fuel system of foreign tractors, and the meter monitor was installed in the tractor cabin (Figure 1, 2). The flow meter is designed for volume and weight measurements of diesel fuel consumed by tractors of a drawbar category of 3--6 tons during various agricultural operations. This flow meter can be used to normalize fuel consumption in agricultural enterprises.

The flow meter is used to measure and record the following data on diesel fuel consumption: specific fuel consumption over the experiment (operation) $(\mathrm{kg} / \mathrm{h})$; time of experiment (sec); fuel consumption by pump (kg); fuel flow at discharge (kg); fuel temperature in a tank and at discharge $\left({ }^{\circ} \mathrm{C}\right)$; specific fuel consumption during display mode (I/h); fuel consumption during display mode (I); display mode time (sec)
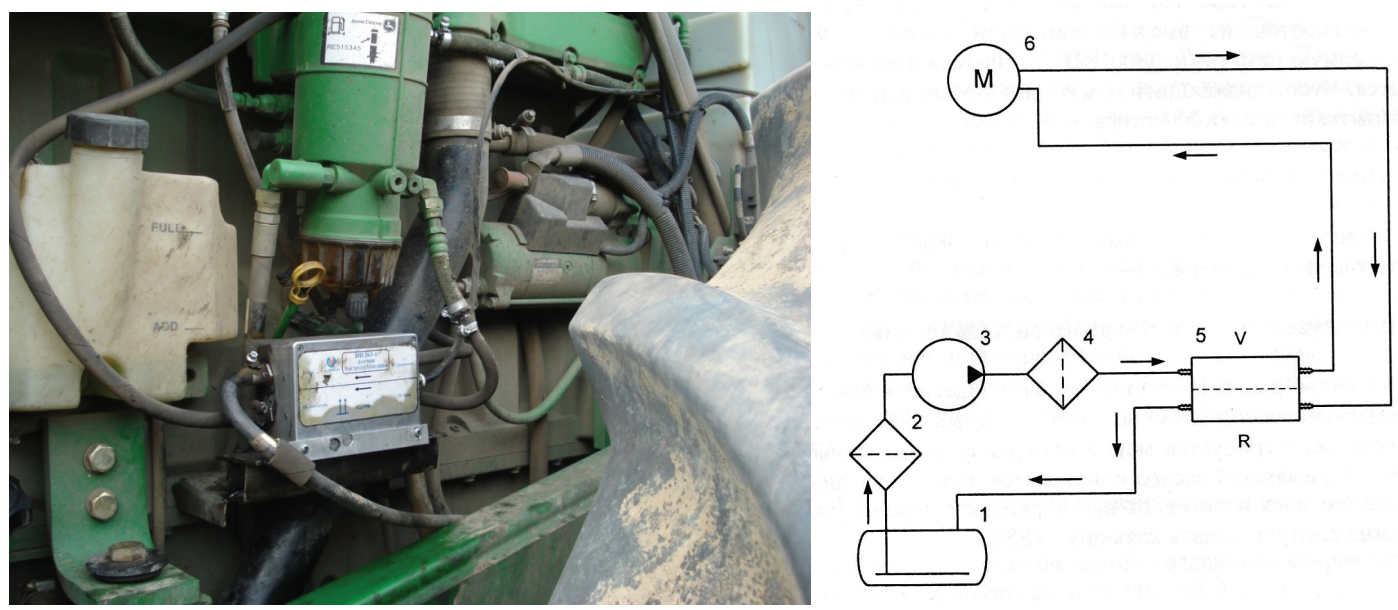

Figure 1: Flow meter in tractor fuel system John Deere-9420: 1 -- fuel tank; 2 -- coarse filter; 3 -- pumping unit (pump); 4 -- fine filter; 5 -- module of primary transmitters; 6 -- diesel engine; $V$-- fuel supply; $R$-- fuel return; $\rightarrow$-- direction of fuel motion.
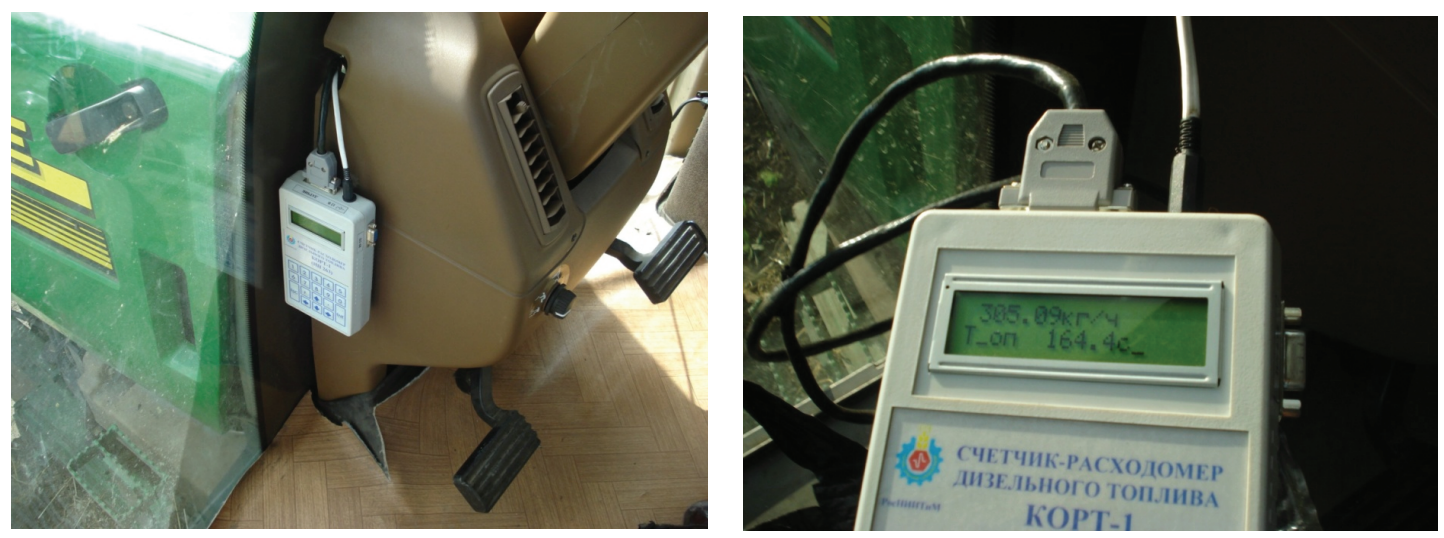

Figure 2: Flow meter parameters during operation of a machine tractor unit as part of the John Deere 9420 with DCM-8x4P disk header.

The flow meter consists of the following units: a fuel gauge and an electronic module. Table 1 shows the basic technical data of diesel fuel flow meter IP 263 RE. 
TABLE 1: Basic technical data of a flow meter.

Parameter
Fuel consumption boundaries, $\mathrm{l} / \mathrm{h}$
Accuracy readability of fuel volume, $\mathrm{cm}^{3} / \mathrm{cts}$, not more
Allowable relative error of fuel consumption value in working conditions,
$\%$, not more
Accuracy readability of electronic module IP-263-2 during fuel
consumption measurement, I/h
Measurement limit of a temperature sensor DS1820, ${ }^{\circ} \mathrm{C}$
Computer communication interface
Absolute error of measurement of a temperature sensor, ${ }^{\circ} \mathrm{C}$, not more
Supply voltage (from on-board electric system of tested agricultural
machines), $\mathrm{V}$
Energy input, W, not more
Nonvolatile memory, Kb
Operating mode time, min, not more
Overall dimensions, mm, not more:
-- electronic module
-- fuel gauge

\begin{tabular}{|c|}
\hline Indication \\
from 30 to 300 \\
13.5 \\
3 \\
0.1 \\
\hline from --10 to +85 \\
\hline RS-232 \\
\pm 0.5 \\
\hline from 10 to 30 \\
\hline 5 \\
\hline 32 \\
\hline 0.5 \\
\hline $200 \times 115 \times 115$ \\
\hline
\end{tabular}

Shift working time utilization factor was calculated according to timing data taking into account the following: shift time; obtaining a work order and handing over of works; all moves; idle runs; routine breaks; time to satisfy physiological needs; daily maintenance.

For example, the productivity of a tractor in the conditions of LLC SP Kolchenskoe for a field located at a distance of 5--6 km and the average length of furrow amounting to $1300 \mathrm{~m}$ can be within $5.8--6.0 \mathrm{ha} / \mathrm{h}$.

\section{Results}

Table 2 shows the results of the study on the definition of fuel consumption and production rate of machine-tractor units as part of John Deere tractors.

The standard consumption of lubricants for agricultural tractors is set as a fraction (\%) of the standard fuel consumption. Taking into account natural and climatic conditions of Tyumen Region and different physical and mechanical composition of soils, as well as the configuration of fields and the length of furrow during processing, Table 3 shows data on the consumption of the main lubricants. 


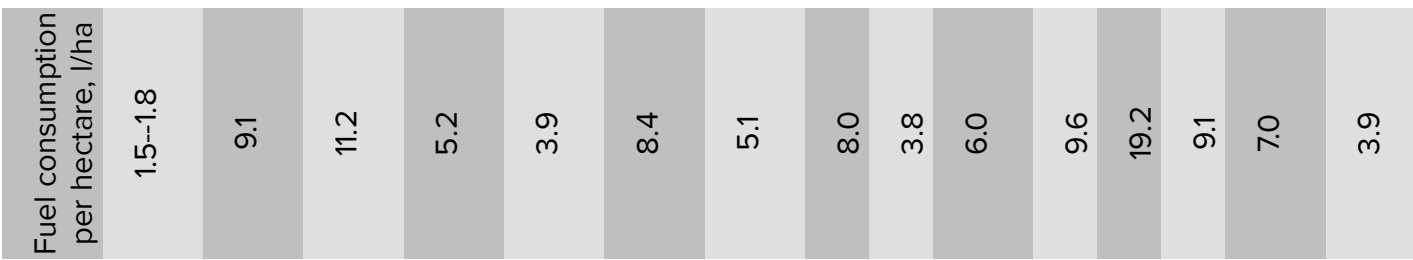

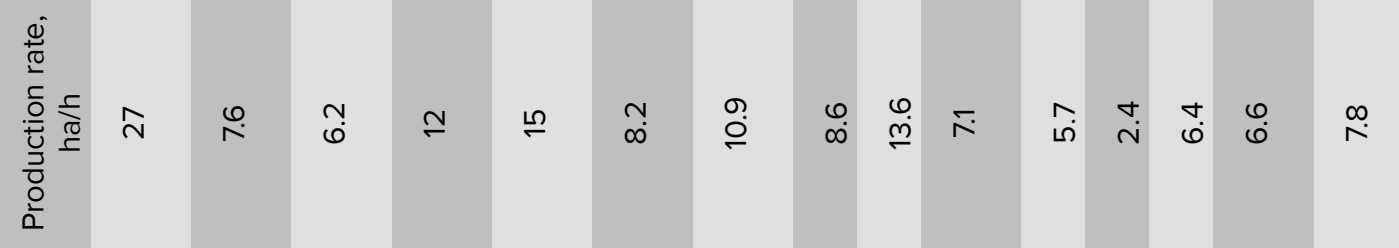

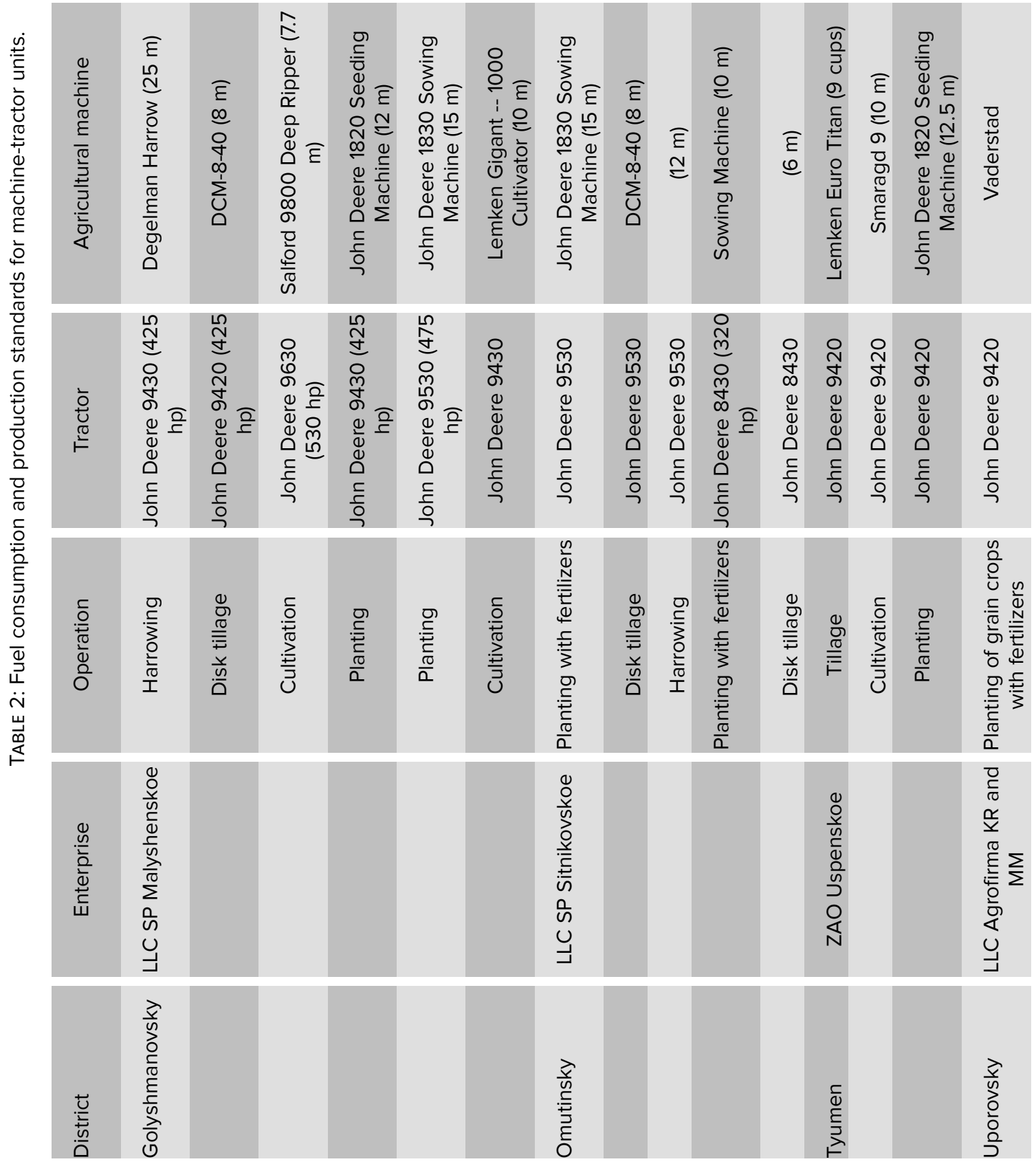


Different types of soils have different effects on the resistance of agricultural aggregates. Table 3 shows the developed recommendations on correction factors applied to normalized fuel consumption depending on soil types for John Deere 9 Series tractors using the example of disk tillage.

In modern conditions, there are three methods to calculate the rational composition of MTF in order to optimize the work of agricultural enterprises [4].

TABLE 3: Standard consumption of lubricants for John Deere tractors (in \% of fuel consumption).

Tractor
John Deere 8430 (320 hp)
John Deere 9420 (425 hp)
John Deere 9430 (425 hp)
John Deere 9530 (475 hp)

\begin{tabular}{|c|}
\hline Motor oils \\
\hline 2.4 \\
\hline 3.1 \\
\hline 3.1 \\
\hline 3.6 \\
\hline
\end{tabular}

$\begin{gathered}\text { Transmission } \\ \text { gear oils }\end{gathered}$
0.4
0.6
0.6
0.7

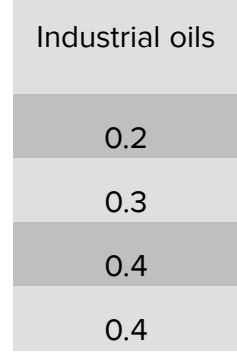

\begin{tabular}{|c|}
\hline $\begin{array}{c}\text { Semisolid } \\
\text { lubricants }\end{array}$ \\
\hline 0.2 \\
\hline 0.3 \\
0.3 \\
\hline 0.3 \\
\hline
\end{tabular}

TABLE 4: Recommendations on application of correction factors to normalized fuel consumption depending on soil types.

Soil
Soddy podzolic light loamy
Soddy podzolic medium loamy
Forest-steppe dark gray, heavy
loamy
Podzolized heavy loamy
chernozem
Leached gumbo chernozem
Heavy loamy chernozem
Medium loamy chernozem
Ordinary gumbo chernozem
Southern gumbo chernozem

\begin{tabular}{|c|c|}
\hline \multicolumn{2}{|c|}{ Soil moisture, $\%$} \\
\hline absolute & relative \\
\hline $2--15$ & $11--55$ \\
\hline $3--20$ & $11--17$ \\
\hline $20--23$ & -- \\
\hline $4--27--37$ & $13--77--108$ \\
\hline 23 & -- \\
\hline $7--16$ & $21--47$ \\
\hline $6--27$ & $19--88$ \\
\hline $10--20--30$ & $24--48--72$ \\
\hline $5--20--30$ & -- \\
\hline
\end{tabular}

\begin{tabular}{|c|c|}
\hline $\begin{array}{c}\text { Frictional drag } \\
\text { coefficient }\end{array}$ & $\begin{array}{c}\text { Correction } \\
\text { factor, } \mathrm{K}_{p}\end{array}$ \\
\hline $0.4--0.5$ & $0.8 \ldots . .9$ \\
\hline $0.4--0.8$ & $0.8 \ldots . .95$ \\
\hline $0.5--0.8$ & 1.0 \\
\hline $0.4--1.0--0.3$ & $0.8 \ldots 1.1$ \\
\hline 0.7 & 0.85 \\
\hline $0.4--0.7$ & $0.8 \ldots . .0 .85$ \\
\hline $0.5--0.8$ & 1.0 \\
\hline $0.7--0.8--1.1$ & $1.1 \ldots 1.2$ \\
\hline $0.3--0.6--0.5$ & $0.7 \ldots 0.8$ \\
\hline
\end{tabular}

The first method is graphoanalytical method. Grade and numerical composition of tractors is defined according to machine utilization schedule. Besides, the definition of MTF composition is linked to multiple revised estimation of machine loading. The adjustment of the number of tractors over the "peak" period is not obvious.

The second method is the calculation of MTF composition on a computer based on economic and mathematical model according to one or more optimization criteria. 
Such criteria may include the minimum of costs for the given costs, for the number of power machines, for the number of mechanizers.

The third method is normative, i.e. based on recommendations of research institutions. The composition of MTF regions is suggested per 1000 hectares of farmland for different regions. However, all tractor plants have now switched to the production of new tractor models, and imported equipment is increasingly being used. These regulations can be conditional.

The most appropriate method is to calculate the rational composition of MTF on PC thus covering the whole variety of input data.

Based on the results of MTF optimization at typical farms it is possible to determine the standards of demand for tractors and agricultural machines for the processing of 1000 hectares of farmland for a specific region of the country.

A software for economic evaluation of agricultural machinery as part of agricultural technology was developed at the Department of Technical Systems in Agro-Industrial Complex of the State Agrarian University of Northern Trans-Urals [5]. The developed engineering application and a program for electronic computers enable chief specialists of farms to quickly carry out the necessary calculations and choose the most effective option to justify the machine-tractor fleet taking into account the shortage of money, labor and other resources of a particular farm.

The software ensures the following tasks:

- comparative economic assessment of tested complexes (tillage, planting, handling of plants, harvesting);

- database on new machinery (tested agricultural machinery);

- analysis of GPS data to evaluate the production of combine harvesters.

The program includes the initial agricultural machinery database (Figure 3), initial regulatory database (Figure 4).

This program is based on the methods of evaluation of new agricultural machinery proposed by the Russian Research Institute for Testing Agricultural Technologies and Machines.

\section{Conclusion}

Fuel and lubricants consumption standards can be increased when operating at a stable average air temperature below the norm; when working in locality with complex relief; 


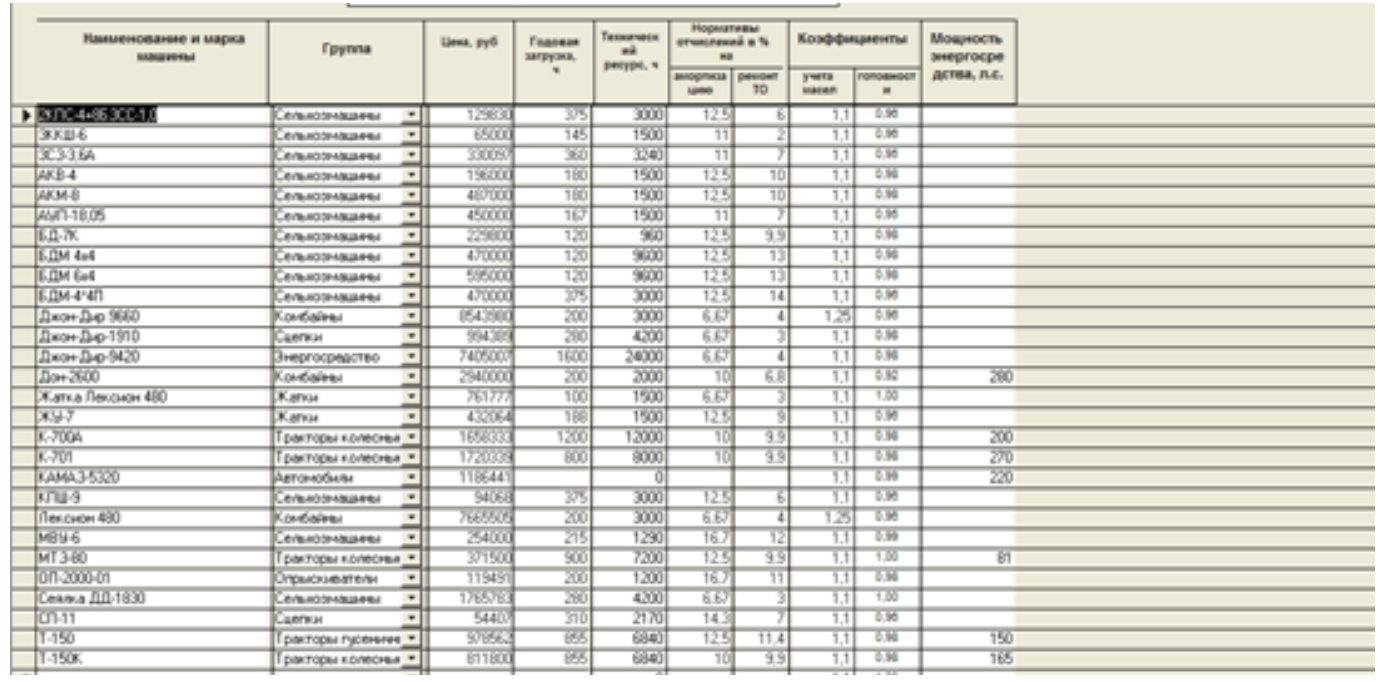

Figure 3: Agricultural machinery database.

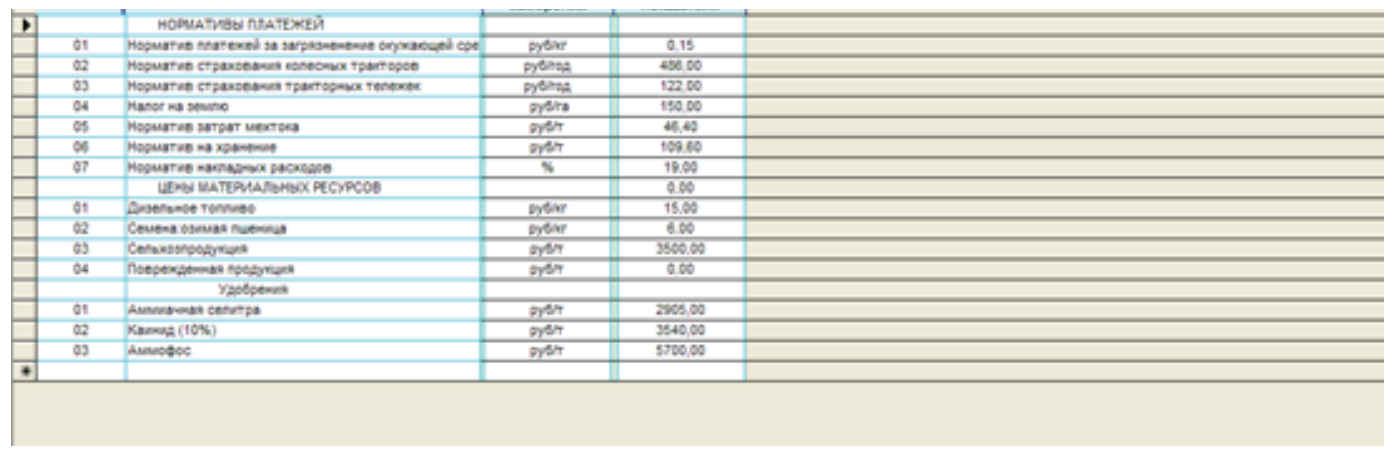

Figure 4: Standard payments and material resources.

when working with frequent stops and maneuvers (taking into account the geometric shape of fields and the length of furrow); in test and training mode (with a trainee); when operating the equipment of machine and tractor unit in the test run mode.

Recommendations on the use of fuel-lubricant consumption standards of modern tractors in various technological operations in agriculture will greatly facilitate planning and calculation of operating costs of machine and tractor units.

\section{Conflict of Interest}

The author has no conflict of interest to declare.

\section{References}

[1] Li, X., Songlin, S., Mingtao, X. Agricultural Machinery Automation and Intelligent Research and Application. IOP Conference Series: Materials Science and 
Engineering, vol. 452.

[2] Kipriyanov, F.A., Medvedeva, N.A., Medvedeva, S.V. Ensuring the operational reliability of the tractor fleet. IOP Conference Series: Earth and Environmental Science, vol. 315, no. 6.

[3] Khramchenkova, A.O. (2016). Updating the standardization method of mechanized field works performed by modern imported equipment. Agro-food policy of Russia, no. 10(58), pp. 23--25.

[4] Dokin1, B.D., Aletdinova, A.A., Kravchenko, M.S., Tsybina, Y.S. Process Approach for Modeling of Machine and Tractor Fleet Structure. Journal of Physics: Conference Series, vol. 1015.

[5] Ustinov, N.N., Ivanov, A.S. (2017). Economic assessment of agricultural machinery as part of agricultural technology using software. World of Innovation, no. 3--4, pp. 70--76. 